\title{
Benzodiazepines and risk of all cause mortality in adults: cohort study
}

\author{
Elisabetta Patorno, Robert J Glynn, Raisa Levin, Moa P Lee, Krista F Huybrechts
}

Division of

Pharmacoepidemiology and

Pharmacoeconomics,

Department of Medicine,

Brigham and Women's Hospital,

Harvard Medical School,

Boston, MA 02120, USA

Correspondence to: E Patorno epatorno@bwh.harvard.edu

Additional material is published online only. To view please visit

the journal online.

Cite this as: BMJ 2017;358:j2941

http://dx.doi.org/10.1136/bmj.j2941

Accepted: 4 June 2017

\section{ABSTRACT \\ OBJECTIVES}

To evaluate the risk of all cause mortality associated with initiating compared with not initiating

benzodiazepines in adults, and to address potential treatment barriers and confounding related to the use of a non-active comparator group.

DESIGN

Retrospective cohort study.

\section{SETTING}

Large de-identified US commercial healthcare database (Optum Clinformatics Datamart).

\section{PARTICIPANTS}

1:1 high dimensional propensity score matched cohort of benzodiazepine initiators, and randomly selected benzodiazepine non-initiators with a medical visit within 14 days of the start of benzodiazepine treatment ( $n=1252988$ ), between July 2004 and December 2013. To address treatment barriers and confounding, patients were required to have filled one or more prescriptions for any medication in the 90 days and 91-180 days before the index date (ie, the date of starting benzodiazepine treatment for initiators and the date of the selected medical visit for benzodiazepine non-initiators) and the high dimensional propensity score was estimated on the basis of more than 300 covariates.

\section{MAIN OUTCOME MEASURE}

All cause mortality, determined by linkage with the Social Security Administration Death Master File.

\section{RESULTS}

Over a six month follow-up period, 5061 and 4691 deaths occurred among high dimensional propensity score matched benzodiazepine initiators versus non-initiators ( 9.3 V 9.4 events per 1000 person years; hazard ratio $1.00,95 \%$ confidence interval 0.96 to 1.04). A 4\% (95\% confidence interval $1 \%$ to $8 \%$ ) to $9 \%(2 \%$ to $7 \%$ ) increase in mortality risk was observed associated with the start of benzodiazepine treatment for follow-ups of 12 and 48 months and in subgroups of younger patients and patients initiating short acting agents. In secondary analyses comparing 1:1 high dimensional propensity score matched patients initiating benzodiazepines with an active comparator, ie, patients starting treatment with selective serotonin reuptake inhibitor antidepressants, benzodiazepine use was associated with a 9\% (95\% confidence interval $3 \%$ to $16 \%$ ) increased risk.

\section{CONCLUSIONS}

This large population based cohort study suggests either no increase or at most a minor increase in risk of all cause mortality associated with benzodiazepine initiation. If a detrimental effect exists, it is likely to be much smaller than previously stated and to have uncertain clinical relevance. Residual confounding likely explains at least part of the small increase in mortality risk observed in selected analyses.

\section{Introduction}

Benzodiazepines are one of the most commonly prescribed classes of psychotropic drugs in developed countries. ${ }^{1}$ In 2008, approximately $5.2 \%$ of US adults aged 18 to 80 years used benzodiazepines in an outpatient setting, ${ }^{2}$ with use increasing from $4.1 \%$ in 1996 to $5.6 \%$ in $2013 .{ }^{3}$ Similarly, an estimated $8.4 \%$ of the population in British Columbia, Canada used a benzodiazepine in 2006, and 5.8\% up to $16.3 \%$ used benzodiazepines across several European countries in $2008 .{ }^{4}$ Use seems to increase with age, with a higher proportion of any and long term use among patients aged more than 50 years. ${ }^{2}$ Because of their established efficacy, ${ }^{5-7}$ benzodiazepines are widely used in the treatment of anxiety and sleep disorders, ${ }^{189}$ which together with mood disorders have been found to be the most common indications for a prescription for benzodiazepines by the US Medical Expenditure Panel Survey in 2013. ${ }^{3}$

Despite earlier mixed results about a possible association between benzodiazepines and all cause mortality, ${ }^{10}$ and mostly no indication of an increased risk among patients aged 65 years or older beyond falls and fractures related mortality, ${ }^{11-14}$ more recent evidence has reported a threefold or higher increase in the risk of all cause mortality among adult populations using benzodiazepines, ${ }^{1516}$ even for durations shorter than one month. Moreover, several studies conducted in adult or young adult populations have not provided support for a specific effect of benzodiazepines that could explain the increased risk in all cause mortality but have rather suggested associations with a wide range of causes of death, including cardiovascular disease, ${ }^{17-20}$ cancer, ${ }^{15}{ }^{18-21}$ respiratory disease, ${ }^{20}$ and suicide..$^{181922}$ 
Although these studies included large populations and yielded precise estimates in a few instances, several concerns remain, such as lack of specificity of the effect and strong associations across a spectrum of different outcomes, unclear biological mechanisms, and several potentially important study design limitations, including confounding and selection bias.

Given the large number of people who use benzodiazepines and the severity of the outcome, the posited strong associations between benzodiazepines and mortality have important public health implications. We therefore evaluated the risk of all cause mortality associated with use of benzodiazepines in a large commercial US health insurance database, mitigating the impact of confounding through specific study design and analytic strategies.

\section{Methods}

\section{Sources of data}

We collected data from Optum Clinformatics Datamart (OptumInsight, Eden Prairie, MN), a large US commercial insurance database covering more than 14 million people annually from all 50 US states. For each participant, the dataset contains demographic information, health plan enrollment status, inpatient and outpatient medical encounters (coded using the international classification of diseases, ninth revision, clinical modification, and current procedural terminology, fourth edition), and drugs filled on an outpatient basis, including the national drug code numbers, quantity dispensed, and days' supply. Data were available from January 2004 through December 2013.

\section{Study population, medication use, and outcome definition}

The exposed study population included patients aged 18 years and older who started a benzodiazepine (see eTable

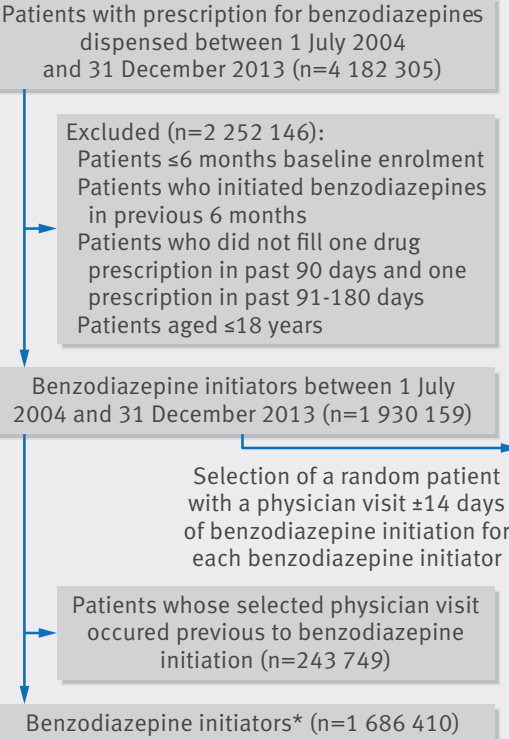

Patients with prescription for benzodiazepines dispensed between 1 July 2004 and 31 December $2013(n=4182305)$

Excluded ( $n=2252146)$

Patients $\leq 6$ months baseline enrolment Patients who initiated benzodiazepines in previous 6 months

Patients who did not fill one drug prescription in past 90 days and one prescription in past $91-180$ days Patients aged $\leq 18$ years

Benzodiazepine initiators between 1 July 2004 and 31 December 2013 ( $n=1930$ 159)

Selection of a random patient with a physician visit \pm 14 days of benzodiazepine initiation for each benzodiazepine initiato

atients whose selected physician visit initiation $(n=243749)$

Benzodiazepine initiators* $(n=1686410)$

For patients contributing to both cohorts of benzodiazepine initiators and non-initiators, only first cohort entry was considered, so that patients who initiated benzodiazepines during study period could serve as non-initiators if selected before drug initiation. As a result, the larger number of benzodiazepine non-initiators is slightly larger

Fig 1 | Flowchart of study cohort
1 in supplementary appendix for a list of benzodiazepines) between 1 July 2004 and 31 December 2013, and had six months of continuous health plan enrollment before drug initiation-that is, the index date for patients who start benzodiazepines (fig 1). We defined benzodiazepine initiators as those who had no use of any benzodiazepine in the previous six months. Patients were not allowed to enter the study cohort more than once. We opted for a primary non-active comparator group because the entire benzodiazepine class has been previously associated with an increased mortality risk, which precludes the use of a within class comparator, and because benzodiazepines have a wide range of indications and uses, which makes the selection of an appropriate out-of-class comparator group challenging. Non-users can have quite different characteristics from benzodiazepine initiators, such as a lower burden of comorbidities, and thus a lower mortality risk, or conversely higher barriers to treatment and surveillance for comorbidities, and thus a higher mortality risk ${ }^{23}$; both scenarios will need to be accounted for through proper study design or analysis choices, or both. To select patients who did not start benzodiazepine treatment with similar opportunity to be evaluated and treated by a physician as patients who started benzodiazepines and within a similar time window, for each benzodiazepine user we identified a random patient who had a medical visit within 14 days either way of the treatment start date for the corresponding benzodiazepine user and fulfilled the same inclusion criteria as benzodiazepine new users-that is, six months of continuous health plan enrollment before the selected medical visit and no use of any benzodiazepine in the six months before and including the date of the visit (ie, the index date for patients who did not start benzodiazepines). We also required patients who either did or did not start benzodiazepines to have at least one filled prescription in the 90 days before the index date and at least one filled prescription in the previous 91 through 180 days, to balance surveillance between groups and to make sure that patients in both groups were in contact with the healthcare system and had equal treatment opportunity. Starting from the patients with the earliest date for starting benzodiazepines in the study period, we repeated these steps for each patient who started benzodiazepines throughout the study period until the last such patient was identified. For patients contributing to both cohorts of users and non-users of benzodiazepines, we only considered the first cohort entry (see supplementary appendix eFigure 1 for study diagram).

Follow-up began on the day after the index date for both cohorts. Patients were followed in an intention-totreat approach until the occurrence of death, nursing home admission, end of continuous health plan enrollment, end of the study period (31 December 2013), or end of the observation period, whichever came first. Consistent with an intention-to-treat approach, we disregarded treatment variations occurring during the follow-up for both cohorts. We considered a six month observation period (180 days) in the main analysis and observation periods of 12 and 48 months of follow-up in sensitivity analyses. A 180 day observation period was chosen for the primary analysis as we empirically 
observed that in routine care approximately two thirds of patients who start benzodiazepines stop treatment within the first two months.

The study outcome was all cause mortality identified by linkage of the Optum Clinformatics Datamart database with the Social Security Administration Death Master File. ${ }^{24}$ The specificity of this master file for detecting mortality status has been estimated to range between $97 \%$ and $100 \% .2526$

\section{Characteristics of patients}

Patient characteristics were identified during the six months preceding and including the index date and included demographic information (age, sex), calendar year, comorbidities and lifestyle factors, use of medications, and indicators of healthcare utilization. We purposely considered a large number of patient characteristics to capture both overt risk factors for mortality and variables that may be proxies of risk factors that were unmeasured or incompletely measured in our dataset. Supplementary appendix eTable 2 shows the complete list of patient characteristics.

\section{Statistical analysis}

We cross tabulated patient baseline characteristics by those who started or did not start benzodiazepines, and in both groups we calculated number of mortality events and incidence rates. Cox proportional hazards analyses were used to estimate hazard ratios with 95\% confidence intervals for the association between benzodiazepines and all cause mortality. Results are presented for three levels of adjustment: unadjusted, adjusted using 1:1 propensity score matching, to control for measured confounders ${ }^{27}$; and adjusted using 1:1 high dimensional propensity score matching, to further control for potential residual confounding. ${ }^{28}$ Exposure propensity scores were derived from the predicted probability of benzodiazepine treatment estimated in a logistic regression model that contained all patient characteristics (see supplementary eTable 2) without additional variable selection. Groups were 1:1 matched on their propensity score using a nearest neighbour matching algorithm without replacement. ${ }^{29}$ We calculated absolute standardized differences to assess covariate balance before and after propensity score matching. ${ }^{30}$ Through the high dimensional propensity score algorithm, an automated technique that identifies and prioritizes covariates that may serve as proxies for unmeasured confounders in large electronic healthcare databases, ${ }^{28}$ we selected a total of 200 empirically identified confounders and combined these with the investigator identified covariates (see supplementary appendix eTable 2) to estimate an empirically enriched propensity score. Stratification on the propensity score matched and high dimensional propensity score matched pair in Cox proportional hazards models to account for potential informative censoring did not change the point estimates appreciably, so this was omitted from all the adjusted analyses.

To test the robustness of our primary findings we performed subgroup and sensitivity analyses. Firstly, we varied the definition of exposure risk window and extended the observation period to 12 and 48 months of follow-up. Secondly, as greater risks for outcomes associated with the hypnotic effects of benzodiazepines have been found among older patients ${ }^{31}$ and possibly among users of benzodiazepines with longer half lives, ${ }^{32} 33$ we tested the potential for effect modification of benzodiazepines on mortality according to age categories ( $<65$ years and $\geq 65$ years) and duration of action (short acting and long acting, ie, $<24$ hours half life and $\geq 24$ hours half life) (see supplementary appendix eTable 3). ${ }^{34}$ For these analyses, we estimated separate propensity scores for each subgroup. Thirdly, to address potential residual confounding associated with the use of a non-active comparator, we explored the use of an active comparator and performed analyses comparing initiators of benzodiazepines with initiators of selective serotonin reuptake inhibitor (SSRI) antidepressants for risk of all cause mortality. We chose SSRIs as the active comparator group because benzodiazepines and SSRIs are both psychotropic drugs and have some overlap in underlying indications, and because SSRIs have no known association with mortality, except for a possible association with increased suicidality in children and young adults. ${ }^{3536}$

All analyses were done using SAS 9.3 Statistical Software (SAS Institute, Cary, NC).

\section{Patient involvement}

No patients were involved in setting the research question or the outcome measures, nor were they involved in developing plans for design or implementation of the study. No patients were asked to advise on interpretation or writing up of results. There are no plans to disseminate the results of the research to study participants or the relevant patient community.

\section{Results}

\section{Study cohort and patient characteristics}

Overall, 4182305 patients had filled a prescription for a benzodiazepine and 35626849 patients had a physician visit between July 2004 and December 2013 in the study database. After application of inclusion and exclusion criteria and random selection of comparison patients with a physician visit within 14 days either way of starting a benzodiazepine, our analytic sample included 1686410 patients who had started a benzodiazepine and 1930159 patients who had not but underwent a medical visit (fig 1). A total of 243749 patients who had started benzodiazepines were excluded because they were selected as patients who had not started treatment before they started benzodiazepine. Short acting benzodiazepines were more frequently prescribed than long acting benzodiazepines, representing approximately $75 \%$ of filled prescriptions. Alprazolam was the most commonly prescribed agent among short acting benzodiazepines (47.2\%), and diazepam was the most commonly prescribed agent among long acting benzodiazepines $(87.7 \%)$.

Table 1 presents selected patient characteristics (see supplementary appendix eTable 2 for a complete list). 


\section{Table 1 | Selected baseline characteristics of study participants before and after high dimensional propensity score matching. Values are percentages} unless stated otherwise

\begin{tabular}{|c|c|c|c|c|c|c|}
\hline \multirow[b]{2}{*}{ Characteristics } & \multicolumn{3}{|c|}{ Before propensity score matching } & \multicolumn{3}{|c|}{ After propensity score matching } \\
\hline & $\begin{array}{l}\text { Benzodiazepine } \\
\text { initiators } \\
(\mathrm{n}=1686410)\end{array}$ & $\begin{array}{l}\text { Benzodiazepine } \\
\text { non-initiators } \\
(n=1930159)\end{array}$ & $\begin{array}{l}\text { Absolute } \\
\text { standardized } \\
\text { differences }\end{array}$ & $\begin{array}{l}\text { Benzodiazepine } \\
\text { initiators } \\
(n=1252988)\end{array}$ & $\begin{array}{l}\text { Benzodiazepine } \\
\text { non-initiators } \\
(n=1252988)\end{array}$ & $\begin{array}{l}\text { Absolute } \\
\text { standardized } \\
\text { differences }\end{array}$ \\
\hline \multicolumn{7}{|l|}{ Demographics: } \\
\hline Mean (SD) age (years) & $46.4(13.8)$ & $43.6(14.6)$ & 0.20 & $46.0(13.8)$ & $45.2(14.6)$ & 0.06 \\
\hline Men & $534592(35.1)$ & $770133(34.6)$ & 0.17 & $439799(35.1)$ & $433534(34.6)$ & 0.01 \\
\hline \multicolumn{7}{|l|}{ Comorbidities and life style factors: } \\
\hline Mean (SD) Charlson comorbidity score & $0.5(1.2)$ & $0.4(0.9)$ & 0.18 & $0.5(1.1)$ & $0.4(1.0)$ & 0.01 \\
\hline Smoking & $94439(5.6)$ & $71416(3.7)$ & 0.09 & $56384(4.5)$ & $56384(4.5)$ & 0.00 \\
\hline Obesity or overweight & $77575(4.6)$ & $75276(3.9)$ & 0.03 & $53878(4.3)$ & $52625(4.2)$ & 0.00 \\
\hline Hypertension & $468822(27.8)$ & $424635(22)$ & 0.13 & $320765(25.6)$ & $325777(26)$ & 0.01 \\
\hline Congestive heart failure & $28669(1.7)$ & $21232(1.1)$ & 0.05 & $17542(1.4)$ & $17542(1.4)$ & 0.00 \\
\hline Ischemic heart disease & $94439(5.6)$ & $75276(3.9)$ & 0.08 & $61396(4.9)$ & $62649(5)$ & 0.00 \\
\hline Cerebrovascular disease & $32042(1.9)$ & $21232(1.1)$ & 0.07 & $13783(1.1)$ & $13783(1.1)$ & 0.00 \\
\hline Other cardiovascular diseases & $102871(6.1)$ & $79137(4.1)$ & 0.09 & $63902(5.1)$ & $63902(5.1)$ & 0.00 \\
\hline Hyperlipidemia & $441839(26.2)$ & $426565(22.1)$ & 0.10 & $310741(24.8)$ & $315753(25.2)$ & 0.01 \\
\hline Diabetes & $163582(9.7)$ & $171784(8.9)$ & 0.03 & $120287(9.6)$ & $121540(9.7)$ & 0.00 \\
\hline Chronic obstructive pulmonary disease & $55652(3.3)$ & $36673(1.9)$ & 0.09 & $32578(2.6)$ & $31325(2.5)$ & 0.01 \\
\hline Asthma & $101185(6)$ & $84927(4.4)$ & 0.07 & $65155(5.2)$ & $65155(5.2)$ & 0.00 \\
\hline Pneumonia & $32042(1.9)$ & $25092(1.3)$ & 0.05 & $20048(1.6)$ & $20048(1.6)$ & 0.00 \\
\hline Osteoarthritis & $118049(7)$ & $94578(4.9)$ & 0.09 & $75179(6)$ & $76432(6.1)$ & 0.00 \\
\hline Other osteoarthritis and musculoskeletal disorders & $489059(29)$ & $440076(22.8)$ & 0.14 & $324524(25.9)$ & 324524 (25.9) & 0.00 \\
\hline Neuropathic pain & $202369(12)$ & $142832(7.4)$ & 0.16 & $119034(9.5)$ & $119034(9.5)$ & 0.00 \\
\hline Back pain & $382815(22.7)$ & $285664(14.8)$ & 0.20 & $233056(18.6)$ & $233056(18.6)$ & 0.00 \\
\hline Fractures & $45533(2.7)$ & $46324(2.4)$ & 0.02 & $31325(2.5)$ & $30072(2.4)$ & 0.01 \\
\hline Falls & $13491(0.8)$ & $11581(0.6)$ & 0.02 & $8771(0.7)$ & $8771(0.7)$ & 0.00 \\
\hline Kidney disease & $57338(3.4)$ & $46324(2.4)$ & 0.06 & $36337(2.9)$ & $36337(2.9)$ & 0.00 \\
\hline Epilepsy or convulsions & $25296(1.5)$ & $15441(0.8)$ & 0.07 & $13783(1.1)$ & $12530(1)$ & 0.01 \\
\hline Cancer & $192251(11.4)$ & $146692(7.6)$ & 0.13 & $119034(9.5)$ & $120287(9.6)$ & 0.00 \\
\hline Anxiety & $241157(14.3)$ & $90717(4.7)$ & 0.33 & $98986(7.9)$ & $87709(7)$ & 0.03 \\
\hline Insomnia & $96125(5.7)$ & $40533(2.1)$ & 0.19 & $43855(3.5)$ & $38843(3.1)$ & 0.02 \\
\hline Other sleep disorders & $89380(5.3)$ & $65625(3.4)$ & 0.09 & $55131(4.4)$ & $52625(4.2)$ & 0.01 \\
\hline Depression & $274885(16.3)$ & $154413(8)$ & 0.26 & $144094(11.5)$ & $139082(11.1)$ & 0.01 \\
\hline Bipolar disorder & $38787(2.3)$ & $17371(0.9)$ & 0.11 & $17542(1.4)$ & $16289(1.3)$ & 0.01 \\
\hline Psychosis & $11805(0.7)$ & $5790(0.3)$ & 0.06 & $5012(0.4)$ & $5012(0.4)$ & 0.00 \\
\hline Delirium & $11805(0.7)$ & $5790(0.3)$ & 0.06 & $6265(0.5)$ & $5012(0.4)$ & 0.01 \\
\hline Drug or alcohol misuse & $37101(2.2)$ & $23162(1.2)$ & 0.08 & $20048(1.6)$ & $18795(1.5)$ & 0.01 \\
\hline \multicolumn{7}{|l|}{ Medications: } \\
\hline ACE inhibitors & $207428(12.3)$ & $218108(11.3)$ & 0.03 & $154118(12.3)$ & $156624(12.5)$ & 0.01 \\
\hline Angiotensin II receptor blockers & $134913(8)$ & $121600(6.3)$ & 0.07 & $95227(7.6)$ & $95227(7.6)$ & 0.00 \\
\hline$\beta$ blockers & $237784(14.1)$ & $202667(10.5)$ & 0.11 & $162888(13)$ & $161635(12.9)$ & 0.00 \\
\hline Calcium channel blockers & $145031(8.6)$ & $202667(10.5)$ & 0.06 & $101492(8.1)$ & $105251(8.4)$ & 0.01 \\
\hline Thiazide diuretics & $82634(4.9)$ & $77206(4)$ & 0.04 & $57637(4.6)$ & $62649(5)$ & 0.02 \\
\hline Digoxin & $11805(0.7)$ & $9651(0.5)$ & 0.03 & $7518(0.6)$ & $7518(0.6)$ & 0.00 \\
\hline Anticoagulants & $38787(2.3)$ & $34743(1.8)$ & 0.04 & $26313(2.1)$ & $26313(2.1)$ & 0.00 \\
\hline Antiplatelets & $38787(2.3)$ & $32813(1.7)$ & 0.04 & $26313(2.1)$ & $27566(2.2)$ & 0.01 \\
\hline Non-insulin glucose lowering agents & $119735(7.1)$ & $133181(6.9)$ & 0.01 & $88962(7.1)$ & $97733(7.8)$ & 0.03 \\
\hline Insulin & $35415(2.1)$ & $36673(1.9)$ & 0.01 & $25060(2)$ & $27566(2.2)$ & 0.01 \\
\hline Lipid lowering agents & $352460(20.9)$ & 351289 (18.2) & 0.07 & $253104(20.2)$ & $261874(20.9)$ & 0.02 \\
\hline Oral corticosteroids & $227665(13.5)$ & $185295(9.6)$ & 0.12 & $142841(11.4)$ & $146600(11.7)$ & 0.01 \\
\hline NSAIDS & $298495(17.7)$ & $287594(14.9)$ & 0.08 & $199225(15.9)$ & $214261(17.1)$ & 0.03 \\
\hline Opioids & $590244(35)$ & $463238(24)$ & 0.24 & $377149(30.1)$ & $360861(28.8)$ & 0.03 \\
\hline Anticonvulsants & $148404(8.8)$ & $81067(4.2)$ & 0.19 & $76432(6.1)$ & $73926(5.9)$ & 0.01 \\
\hline SSRIS & $377756(22.4)$ & $223898(11.6)$ & 0.29 & $239321(19.1)$ & $189201(15.1)$ & 0.11 \\
\hline Other hypnotics & $195624(11.6)$ & $82997(4.3)$ & 0.27 & $100239(8)$ & $76432(6.1)$ & 0.07 \\
\hline Other anxiolytics & $37101(2.2)$ & $17371(0.9)$ & 0.11 & $20048(1.6)$ & $15036(1.2)$ & 0.03 \\
\hline Antipsychotics & $45533(2.7)$ & $21232(1.1)$ & 0.12 & $21301(1.7)$ & $20048(1.6)$ & 0.01 \\
\hline Barbiturates & $38787(2.3)$ & $21232(1.1)$ & 0.09 & $22554(1.8)$ & $17542(1.4)$ & 0.03 \\
\hline \multicolumn{7}{|l|}{ Indicators of healthcare utilization: } \\
\hline Any hospitalization & $175387(10.4)$ & $133181(6.9)$ & 0.12 & $101492(8.1)$ & $98986(7.9)$ & 0.01 \\
\hline Mean (SD) No of hospital days & $0.8(4.2)$ & $0.5(3.1)$ & 0.09 & $0.6(3.4)$ & $0.6(3.6)$ & 0.00 \\
\hline Mean (SD) No of physician visits & $4.0(3.6)$ & $2.9(2.9)$ & 0.31 & $3.4(3.2)$ & $3.4(3.1)$ & 0.00 \\
\hline Mean (SD) No of prescription drugs & $5.9(4.0)$ & $4.3(3.1)$ & 0.43 & $5.1(3.6)$ & $5.1(3.4)$ & 0.01 \\
\hline Psychiatric visit & $382815(22.7)$ & $210387(10.9)$ & 0.32 & $199225(15.9)$ & $182936(14.6)$ & 0.04 \\
\hline
\end{tabular}

ACE=angiotensin converting enzyme; NSAIDs=non-steroidal anti-inflammatory drugs; SSRIs=selective serotonin reuptake inhibitors. 
We describe the covariates that are either more likely important risk factors for mortality or characterised by large imbalances (absolute standardized difference $>0.1$ ) between patients who initiated and did not initiate benzodiazepines. Compared with patients who did not initiate benzodiazepines, those who did were older, more often female, and had generally a higher burden of comorbidities, as measured by the Charlson comorbidity score. ${ }^{37}$ Benzodiazepine initiators were more likely than non-initiators to have a history of hypertension, ischemic heart disease, heart failure, stroke, hyperlipidemia, diabetes, kidney disease, and cancer, and they were more often characterised by having painful conditions and psychiatric disorders, including anxiety, insomnia, depression, and drug or alcohol misuse. Benzodiazepine initiators were also more likely to use other hypnotic drugs, opioids, and antidepressants and to utilize healthcare more frequently. The prevalence of most characteristics, including the ones with small imbalances across exposure groups (absolute standardized difference $<0.1$ ) before adjustment for high dimensional propensity score, was consistently higher among benzodiazepine initiators than non-initiators. After propensity score matching, all patient characteristics between benzodiazepine initiators and non-initiators were well balanced (table 1), as assessed by absolute standardized differences $<0.1 .^{30}$

In the primary analysis, the overall mean follow-up was 159 (SD 46) days for benzodiazepine initiators and 146 (56) days for non-initiators and the median was 180 days for both groups. Most patients were censored because of the end of the six month follow-up period (77.4\% for benzodiazepine initiators and $65.7 \%$ for non-initiators), followed by the end of continuous health plan enrollment (18.6\% and 30.4\%, respectively).

\section{Absolute and relative hazards \\ Overall, 8945 deaths occurred among benzodiazepine initiators (12.2 events per 1000 person years) and 5347 deaths among non-initiators (6.9 events per 1000 per- son years) within a six month observation period (table 2). Results from the unadjusted Cox regression analysis indicated that benzodiazepine initiators had a $79 \%$ increased risk of mortality compared with non-ini- tiators (hazard ratio $1.79,95 \%$ confidence interval 1.73 to 1.85). However, after 1:1 propensity score matching, the hazard ratio became consistent with no increased risk of death associated with benzodiazepine initiation compared with non-initiation (0.89, 0.85 to 0.93$)$ and moved to 1.00 (0.96 to 1.04 ) in the 1:1 high dimensional propensity score matched population (table 2). High dimensional propensity score matched Kaplan-Meier}

curves comparing the survival probability between benzodiazepine users and non-users were consistent with our findings (fig 2, upper panel).

\section{Sensitivity and subgroup analyses}

When we varied the definition for exposure risk window and extended the observation period to 12 and 48 months of follow-up, we identified a small statistically significant increased risk of mortality among benzodiazepine initiators compared with non-initiators (hazard ratio 1.04, 95\% confidence interval 1.01 to 1.08 and 1.05 , 1.02 to 1.07 , respectively, table 3 ). The middle and lower panels in figure 2 display the Kaplan-Meier curves comparing the survival probability between the high dimensional propensity score matched benzodiazepine initiators versus non-initiators over 12 and 48 months of follow-up.

Stratified analyses by age and by benzodiazepine duration of action showed no increased risk of all cause mortality associated with benzodiazepine initiation among older patients or those initiating benzodiazepines with a longer half life (table 3 ). However, younger patients and patients using short acting benzodiazepines had a statistically significant, small increase in risk of all cause mortality compared with those who did not initiate benzodiazepines (1.09, 1.02 to 1.15 and 1.06, 1.02 to 1.10 , respectively).

When SSRIs were used as the active comparator to benzodiazepines, results from the unadjusted Cox regression analysis indicated that benzodiazepine initiators had a 62\% increased risk of mortality compared with non-initiators (1.61, 1.53 to 1.68$)$. The hazard ratio moved to 1.09 (1.03 to 1.16) after 1:1 high dimensional propensity score matching (table 4).

\section{Discussion}

Using a propensity score matched and high dimensional propensity score matched cohort that included more than 2500000 patients from a large commercial US health insurance database, we found no statistically significant difference in the occurrence of all cause mortality among patients who initiated benzodiazepines compared with non-initiators within a six month follow-up. We observed small, but statistically significant (owing to the large size of the cohort) increases in mortality risk associated with the initiation of benzodiazepines for follow-ups longer than six months, in younger patients, in patients initiating short acting drugs, and in the active comparison with selective serotonin reuptake inhibitor (SSRI) antidepressants. Although these results do not rule out the possibility of a small detrimental effect associated with benzodiazepines, this effect is

\begin{tabular}{|c|c|c|c|c|c|c|c|c|c|}
\hline \multirow[b]{2}{*}{ Analysis } & \multicolumn{4}{|c|}{ Benzodiazepine initiators } & \multicolumn{4}{|c|}{ Benzodiazepine non-initiators } & \multirow[b]{2}{*}{$\begin{array}{l}\text { Hazard ratio } \\
(95 \% \mathrm{Cl})\end{array}$} \\
\hline & $\begin{array}{l}\text { No of } \\
\text { patients }\end{array}$ & $\begin{array}{l}\text { No of } \\
\text { events }\end{array}$ & $\begin{array}{l}\text { Person } \\
\text { years }\end{array}$ & $\begin{array}{l}\text { Incidence } / 1000 \\
\text { person years }\end{array}$ & $\begin{array}{l}\text { No of } \\
\text { patients }\end{array}$ & $\begin{array}{l}\text { No of } \\
\text { events }\end{array}$ & $\begin{array}{l}\text { Person } \\
\text { years }\end{array}$ & $\begin{array}{l}\text { Incidence } / 1000 \\
\text { person years }\end{array}$ & \\
\hline Unadjusted & 1686410 & 8945 & 733918 & 12.2 & 1930159 & 5347 & 772958 & 6.9 & $1.78(1.73$ to 1.85$)$ \\
\hline 1:1 propensity score matched & 1256630 & 4622 & 547803 & 8.4 & 1256630 & 4839 & 503208 & 9.6 & 0.89 (0.85 to 0.93$)$ \\
\hline 1:1 high dimensional propensity score matched & 1252988 & 5061 & 546435 & 9.3 & 1252988 & 4691 & 500932 & 9.4 & $1.00(0.96$ to 1.04$)$ \\
\hline
\end{tabular}




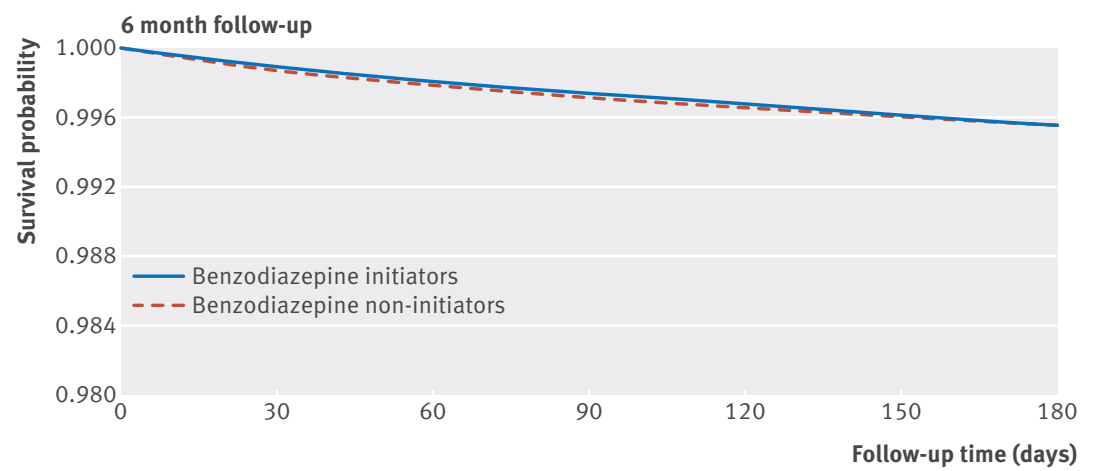

Benzodiazepine initiators

$\begin{array}{lllllll}1252988 & 1203407 & 1154700 & 1106852 & 1060664 & 1016960 & 974209\end{array}$

Benzodiazepine non-initiators

$1252988 \quad 1161649$

$1080457 \quad 1006288 \quad 940312 \quad 879467$

821236

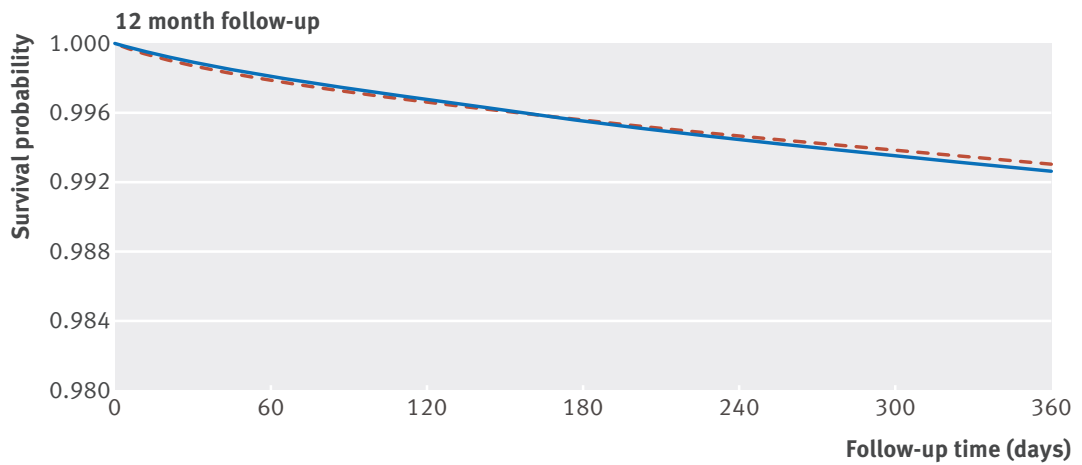

Benzodiazepine initiators

$\begin{array}{rrrrrrr}1252988 & 1154700 & 1060664 & 974209 & 903767 & 837917 & 775104 \\ \text { Benzodiazepine non-initiators } & & & & & \\ 1252988 & 1080457 & 940312 & 821236 & 737706 & 664150 & 598123\end{array}$

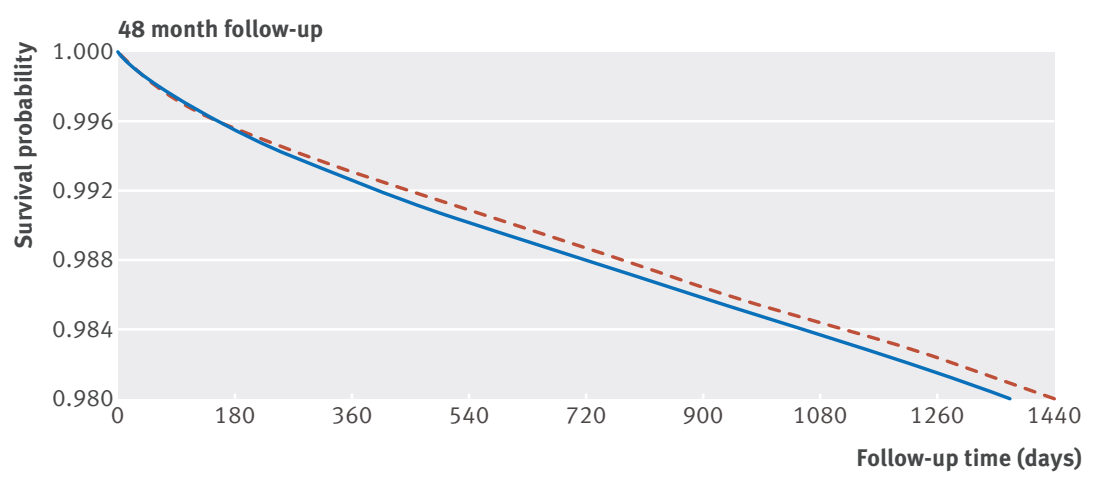

Benzodiazepine initiators

$\begin{array}{llllllllll}1252988 & 974209 & 775104 & 611789 & 493693 & 395513 & 321930 & 260131 & 210795\end{array}$

Benzodiazepine non-initiators

$\begin{array}{lllllllll}1252988 & 821236 & 598123 & 435868 & 332412 & 253780 & 197967 & 153533 & 120706\end{array}$

Fig 2 | High dimensional propensity score matched Kaplan-Meier curves for survival probability since start of follow-up, and number of patients at risk

likely to be much lower than previously proposed..$^{1516}$ Moreover, the direction and extent of the attenuation of the point estimates with high dimensional propensity score adjustment in both the comparisons with benzodiazepine non-initiators and SSRI initiators, and the tight confidence intervals driven by the large size of our study, suggest that residual confounding-rather than a true effect of benzodiazepine drugs-could drive the small increase in mortality risk observed in selected analyses.

Whether there is an effect on the risk of all cause mortality associated with the use of benzodiazepines has been an area of much discussion. The biological mechanism through which benzodiazepines would lead to an increased risk of all cause mortality is unclear. Benzodiazepines confer their effects through their action on $\gamma$-amino-butyric acid (GABA) type A receptors in the central nervous system, which are molecular substrates for the regulation of vigilance, anxiety, muscle tension, epileptogenic activity, and memory functions. ${ }^{38}$ Because of their psychotropic action, benzodiazepines have been associated with hypnotic related side effects such as daytime sleepiness, impairment of psychomotor and cognitive functioning, increased risk of motor vehicle collisions, and increased risk of falls and fractures, ${ }^{39-42}$ in particular among older patients, ${ }^{31}$ and with possible greater risks for benzodiazepines with a longer half life. ${ }^{32} 33$ Benzodiazepines have also been associated with an increased risk for development of dependence and misuse. However, this risk is not as substantial as with older sedatives and other recognised drugs of abuse, ${ }^{43}$ and overdose with a benzodiazepine rarely causes severe cardiovascular or respiratory depression and death. ${ }^{34}$ Yet several studies performed in adult populations have reported strong associations between benzodiazepines and all cause mortality, even for short durations of treatment, 151644 as well as associations with a wide range of causes of deaths, including cardiovascular disease $\mathrm{e}^{17-20}$ and cancer, ${ }^{151819-22}$ for which the biological mechanism leading to an increased risk remains unclear. The lack of specificity of the effect identified in these investigations coexists with several potentially important limitations at the study design and analysis level, the most important being confounding. ${ }^{11456}$ More specifically, it has being suggested that benzodiazepine treatment could be a "marker" for unmeasured underlying conditions resulting in death, rather than being the cause of death in itself. ${ }^{1447}$ In support of this theory, several investigations have shown that health status and a history of multiple chronic conditions are independent predictors of benzodiazepine use. ${ }^{189}$ In line with this theory, we observed a consistently higher prevalence of mortality risk factors among benzodiazepine initiators compared with non-initiators or SSRI initiators, and large attenuations in the point estimates after high dimensional propensity score adjustment for both comparisons. The remaining small increase in risk is likely due to residual confounding. Residual confounding rather than true effect modification may also explain the moderate discrepancy in the risk of all cause mortality between patients aged less than and more than 65 years and between those using short acting and long acting benzodiazepines. In addition, the lack of an increased risk in all cause mortality among benzodiazepine initiators aged more than 65 years and among those initiators long acting agents further suggests that the hypnotic effects of benzodiazepines are likely not responsible for the increased risk observed in previous investigations. 


\begin{tabular}{|c|c|c|c|c|c|c|c|c|c|}
\hline \multirow[b]{2}{*}{ Analysis } & \multicolumn{4}{|c|}{ Benzodiazepine initiators } & \multicolumn{4}{|c|}{ Benzodiazepine non-initiators } & \multirow[b]{2}{*}{ Hazard ratio $(95 \% \mathrm{Cl})$} \\
\hline & $\begin{array}{l}\text { No of } \\
\text { patients }\end{array}$ & $\begin{array}{l}\text { No of } \\
\text { Events }\end{array}$ & $\begin{array}{l}\text { Person } \\
\text { years }\end{array}$ & $\begin{array}{l}\text { Incidence } / 1000 \\
\text { person years }\end{array}$ & $\begin{array}{l}\text { No of } \\
\text { patients }\end{array}$ & $\begin{array}{l}\text { No of } \\
\text { events }\end{array}$ & $\begin{array}{l}\text { Person } \\
\text { years }\end{array}$ & $\begin{array}{l}\text { Incidence/1000 } \\
\text { person years }\end{array}$ & \\
\hline \multicolumn{10}{|c|}{ Follow-up duration (months): } \\
\hline 12 & 1252988 & 7671 & 986396 & 7.8 & 1252988 & 6552 & 855316 & 7.7 & 1.04 (1.01 to 1.08$)$ \\
\hline 48 & 1252988 & 13532 & 2241015 & 6.0 & 1252988 & 10299 & 1696159 & 6.1 & $1.05(1.02$ to 1.07$)$ \\
\hline \multicolumn{10}{|c|}{ Patient age (years): } \\
\hline$<65$ & 1156209 & 2160 & 504932 & 4.3 & 1156209 & 1843 & 462811 & 4.0 & 1.09 (1.02 to 1.15$)$ \\
\hline$\geq 65$ & 92273 & 2599 & 39716 & 65.4 & 92273 & 2708 & 36438 & 74.3 & 0.89 (0.85 to 0.94$)$ \\
\hline \multicolumn{10}{|c|}{ Drug duration of action: } \\
\hline Short acting & 1011732 & 4973 & 440142 & 11.3 & 1011732 & 4370 & 403954 & 10.8 & $1.06(1.02$ to 1.10$)$ \\
\hline Long acting & 412976 & 869 & 181483 & 4.8 & 412976 & 1341 & 165450 & 8.1 & $0.60(0.55$ to 0.65$)$ \\
\hline
\end{tabular}

Table 4 | Risk of mortality associated with benzodiazepine initiation versus selective serotonin reuptake inhibitors (SSRIs) initiation in unadjusted, propensity score and high dimensional propensity score matched analyses

\begin{tabular}{|c|c|c|c|c|c|c|c|c|c|}
\hline \multirow[b]{2}{*}{ Analysis } & \multicolumn{4}{|c|}{ Benzodiazepine initiators } & \multicolumn{4}{|c|}{ SSRI initiators } & \multirow[b]{2}{*}{ Hazard ratio $(95 \% \mathrm{Cl})$} \\
\hline & $\begin{array}{l}\text { No of } \\
\text { patients }\end{array}$ & $\begin{array}{l}\text { No of } \\
\text { Events }\end{array}$ & $\begin{array}{l}\text { Person } \\
\text { years }\end{array}$ & $\begin{array}{l}\text { Incidence } / 1000 \\
\text { person years }\end{array}$ & $\begin{array}{l}\text { No of } \\
\text { patients }\end{array}$ & $\begin{array}{l}\text { No of } \\
\text { events }\end{array}$ & $\begin{array}{l}\text { Person } \\
\text { years }\end{array}$ & $\begin{array}{l}\text { Incidence } / 1000 \\
\text { person years }\end{array}$ & \\
\hline Unadjusted & 1063845 & 6008 & 465228 & 12.9 & 649400 & 2276 & 282646 & 8.1 & 1.61 (1.53 to 1.68$)$ \\
\hline 1:1 propensity score matched & 563088 & 2076 & 245380 & 8.5 & 563088 & 2096 & 245252 & 8.5 & $0.99(0.93$ to 1.05$)$ \\
\hline 1:1 high dimensional propensity score matched & 549022 & 2213 & 239380 & 9.2 & 549022 & 2032 & 239261 & 8.5 & 1.09 (1.03 to 1.16$)$ \\
\hline
\end{tabular}

Strengths and limitations of this study

Our study exhibits several strengths. In this large population based study, which included more than 1250000 high dimensional propensity score matched benzodiazepine initiators, we were able to evaluate the association between benzodiazepines and the risk of all cause mortality among adult patients as treated in a routine care setting. Through the use of a large, nationwide US commercial healthcare database (Optum Clinformatics Datamart), we had access to detailed patient information, including patient's diagnoses, use of medications, and measures of healthcare utilization. The linkage with the Social Security Administration Death Master File ensured that mortality was captured with high specificity, thus minimizing possible bias in the relative risk estimates. To minimize the potential for residual confounding, we employed multiple approaches in the study design and analysis, including the identification of benzodiazepine non-initiators who had similar patterns of healthcare utilization and treatment opportunity as benzodiazepine initiators, and the use of high dimensional propensity score analysis and an active comparator group to address potential unmeasured confounding. We also investigated the potential for effect modification in subgroup analyses by age and patients initiators benzodiazepines with shorter and longer half lives. The focus of the study on a middle aged, employed population, and the exclusion of frail participants who are not employed and not privately insured, may be one of the main advantages of this study as it is likely to control for a great deal of the confounding that may have been present in other studies.

Regardless, the main limitation to be considered remains confounding. Although the Optum Clinformatics Datamart database provides detailed patient information, certain relevant clinical information might not have been completely captured, because it is either not fully or not directly measured in administrative data, and this may have led to residual confounding. We adjusted for confounding by comparing benzodiazepine initiators with non-initiators who had evidence of other medication use before cohort entry to reduce the risk of treatment barriers among non-initiators, and by using high dimensional propensity score methodology and an active comparator group to address potential unmeasured confounding through proxy identification. Despite these efforts, the potential for some residual confounding remains, which may have driven the positive associations observed in selected analyses.

\section{Conclusions}

Results from this large cohort study based on an intention-to-treat approach suggest either no increase or a small increase in the risk of all cause mortality associated with benzodiazepine initiation. If a detrimental effect on all cause mortality exists, it is likely to be much lower than previously stated and to have only modest clinical relevance, given its magnitude from both an absolute and a relative perspective. The direction and the extent of the attenuation in the point estimates with increasing levels of adjustment, suggest that residual confounding likely explains at least part of the small increase in mortality risk observed in selected analyses.

Contributors: EP and KFH were involved in all parts of the study. RL and MPL were involved in data analysis and revising the manuscript RJG was involved in designing the study and revising the manuscript. All authors had full access to all of the data (including statistical reports and tables) in the study and can take responsibility for the integrity of the data and the accuracy of the data analysis. EP and KFH are the guarantors.

Funding: This study was funded by the Division of

Pharmacoepidemiology and Pharmacoeconomics, Brigham and Women's Hospital, Harvard Medical School, Boston, MA. KFH was supported by a career development grant (K01MH099141) from the National Institute of Mental Health. The funders had no role in the design and conduct of the study; collection, management, analysis, 
and interpretation of the data; and preparation, review, or approval of the manuscript.

Competing interests: All authors have completed the ICMJE uniform disclosure form at www.icmje.org/coi disclosure.pdf (available on request from the corresponding author) and declare: EP reports receiving research funding from GSK and Boehringer-Ingelheim, outside the submitted work; RJG reports grants from AstraZeneca and Novartis outside the submitted work; KFH reports grants from Eli Lilly, Pfizer, Boehringer-Ingelheim, and GSK outside the submitted work.

Ethical approval: The use of this dataset for research was approved by the institutional review board (No 2013P000573) of the Brigham and Women's Hospital, Boston, MA and a data use agreement was in place. Data sharing: No additional data available.

Transparency: The manuscript's guarantors (EP and KFH) affirm that the manuscript is an honest, accurate, and transparent account of the study being reported; that no important aspects of the study have been omitted; and that any discrepancies from the study as planned (and, if relevant, registered) have been explained.

This is an Open Access article distributed in accordance with the Creative Commons Attribution Non Commercial (CC BY-NC 4.0) license, which permits others to distribute, remix, adapt, build upon this work non-commercially, and license their derivative works on different terms, provided the original work is properly cited and the use is non-commercial. See: http://creativecommons.org/licenses/ by-nc/4.0/.

1 Cunningham CM, Hanley GE, Morgan S. Patterns in the use of benzodiazepines in British Columbia: examining the impact of increasing research and guideline cautions against long-term use. Health Policy 2010;97:122-9. doi:10.1016/j.healthpol.2010.03.008.

2 Olfson M, King M, Schoenbaum M. Benzodiazepine use in the United States. JAMA Psychiatry 2015;72:136-42. doi:10.1001/ jamapsychiatry.2014.1763.

3 Bachhuber MA, Hennessy S, Cunningham CO, Starrels JL. Increasing Benzodiazepine Prescriptions and Overdose Mortality in the United States. 1996-2013. Am J Public Health 2016;106:686-8. doi:10.2105/ AJPH.2016.303061.

4 Huerta C, Abbing-Karahagopian V, Requena G, et al. Exposure to benzodiazepines (anxiolytics, hypnotics and related drugs) in seven European electronic healthcare databases: a cross-national descriptive study from the PROTECT-EU Project. Pharmacoepidemiol Drug Saf 2016;25(suppl 1):56-65. doi:10.1002/pds.3825.

5 Martin IL, Sainz-Pardo M, Furukawa TA, Martín-Sánchez E, Seoane T, Galán C. Benzodiazepines in generalized anxiety disorder: heterogeneity of outcomes based on a systematic review and meta-analysis of clinical trials. J Psychopharmacol 2007;21:774-82. doi:10.1177/0269881107077355.

6 van Balkom AJ, Bakker A, Spinhoven P, Blaauw BM, Smeenk S, Ruesink B. A meta-analysis of the treatment of panic disorder with or without agoraphobia: a comparison of psychopharmacological, cognitivebehavioral, and combination treatments. J Nerv Ment Dis 1997;185:510-6. doi:10.1097/00005053-199708000-00006

7 Buscemi N, Vandermeer B, Friesen C, et al. The efficacy and safety of drug treatments for chronic insomnia in adults: a meta-analysis of RCTs. J Gen Intern Med 2007;22:1335-50. doi:10.1007/ s11606-007-0251-z.

8 Sonnenberg CM, Bierman EJM, Deeg DJH, Comijs HC, van Tilburg W, Beekman AT. Ten-year trends in benzodiazepine use in the Dutch population. Soc Psychiatry Psychiatr Epidemiol 2012;47:293-301. doi:10.1007/s00127-011-0344-1.

9 Fourrier A, Letenneur L, Dartigues JF, Moore N, Bégaud B. Benzodiazepine use in an elderly community-dwelling population. Characteristics of users and factors associated with subsequent use. Eur / Clin Pharmacol 2001:57:419-25. doi:10.1007/s002280100326.

10 Charlson F, Degenhardt L, McLaren J, Hall W, Lynskey M. A systematic review of research examining benzodiazepine-related mortality. Pharmacoepidemiol Drug Saf 2009;18:93-103. doi:10.1002/pds.1694.

11 Jaussent I, Ancelin ML, Berr C, et al. Hypnotics and mortality in an elderly general population: a 12-year prospective study. BMC Med 2013;11:212. doi:10.1186/1741-7015-11-212.

12 Vinkers DJ, Gussekloo J, van der Mast RC, Zitman FG, Westendorp RG]. Benzodiazepine use and risk of mortality in individuals aged 85 years or older. JAMA 2003;290:2942-3. doi:10.1001/jama.290.22.2942.

13 Hogan DB, Maxwell Cl, Fung TS, Ebly EM. Canadian Study of Health and Aging. Prevalence and potential consequences of benzodiazepine use in senior citizens: results from the Canadian Study of Health and Aging Can / Clin Pharmacol 2003:10:72-7.

14 Rumble R, Morgan K. Hypnotics, sleep, and mortality in elderly people. J Am Geriatr Soc 1992;40:787-91. doi:10.1111/j.1532-5415.1992.tb01850

15 Kripke DF, Langer RD, Kline LE. Hypnotics' association with mortality or cancer: a matched cohort study. BMJ Open 2012;2:e000850. doi:10.1136/bmjopen-2012-000850.
16 Weich S, Pearce HL, Croft P, et al. Effect of anxiolytic and hypnotic drug prescriptions on mortality hazards: retrospective cohort study. BMJ 2014:348:g1996. doi:10.1136/bmi.g1996.

17 Thorogood M, Cowen P, Mann J, Murphy M, Vessey M. Fatal myocardial infarction and use of psychotropic drugs in young women. Lancet 1992;340:1067-8. doi:10.1016/0140-6736(92)93081-W.

18 Kripke DF, Klauber MR, Wingard DL, Fell RL, Assmus JD, Garfinkel L. Mortality hazard associated with prescription hypnotics. Biol Psychiatry 1998;43:687-93. doi:10.1016/S0006-3223(97)00292-8.

19 Mallon L, Broman JE, Hetta J. Is usage of hypnotics associated with mortality?Sleep Med 2009;10:279-86. doi:10.1016/j. sleep.2008.12.004

20 Belleville G. Mortality hazard associated with anxiolytic and hypnotic drug use in the National Population Health Survey. Can J Psychiatry 2010;55:558-67. doi:10.1177/070674371005500904

21 Mallon L, Broman JE, Hetta J. Sleep complaints predict coronary artery disease mortality in males: a 12-year follow-up study of a middle-aged Swedish population. J Intern Med 2002;251:207-16 doi:10.1046/j.1365-2796.2002.00941.x.

22 Tiihonen I, Suokas JT, Suvisaari IM, Haukka J, Korhonen P. Polypharmacy with antipsychotics, antidepressants, or benzodiazepines and mortality in schizophrenia. Arch Gen Psychiatry 2012;69:476-83. doi:10.1001/archgenpsychiatry.2011.1532.

23 Glynn RJ, Knight EL, Levin R, Avorn J. Paradoxical relations of drug treatment with mortality in older persons. Epidemiology 2001;12:6829. doi:10.1097/00001648-200111000-00017.

24 Social Security Administration. Social Security's Death Master File. 2013. https://www.ssa.gov/dataexchange/request_dmf.html Accessed November 18, 2015.

25 Hermansen SW, Leitzmann MF Schatzkin A. The impact on National Death Index ascertainment of limiting submissions to Social Security Administration Death Master File matches in epidemiologic studies of mortality. Am J Epidemiol 2009;169:901-8. doi:10.1093/aje/kwn404.

26 Schisterman EF, Whitcomb BW. Use of the Social Security Administration Death Master File for ascertainment of mortality status. Popul Health Metr 2004;2:2. doi:10.1186/1478-7954-2-2.

27 Rubin DB. Estimating causal effects from large data sets using propensity scores. Ann Intern Med 1997;127:757-63. doi:10.7326/0003-4819-127-8_Part_2-199710151-00064.

28 Schneeweiss S, Rassen JA, Glynn RJ, Avorn J, Mogun H, Brookhart MA. High-dimensional propensity score adjustment in studies of treatment effects using health care claims data. Epidemiology 2009;20:512-22. doi:10.1097/EDE.0b013e3181a663cc.

29 Rassen JA, Glynn RJ, Brookhart MA, Schneeweiss S. Covariate selection in high-dimensional propensity score analyses of treatment effects in small samples. Am J Epidemiol 2011;173:1404-13. doi:10.1093/aje/kwr001.

30 Austin PC. Balance diagnostics for comparing the distribution of baseline covariates between treatment groups in propensity-score matched samples. Stat Med 2009;28:3083-107. doi:10.1002/ sim.3697.

31 Madhusoodanan S, Bogunovic OJ. Safety of benzodiazepines in the geriatric population. Expert Opin Drug Saf 2004;3:485-93. doi:10.1517/14740338.3.5.485.

32 Ray WA, Griffin MR, Downey W. Benzodiazepines of long and short elimination half-life and the risk of hip fracture. JAMA 1989;262:33037. doi:10.1001/jama.1989.03430230088031.

33 de Vries OJ, Peeters G, Elders P et al. The elimination half-life of benzodiazepines and fall risk: two prospective observational studies. Age Ageing 2013;42:764-70. doi:10.1093/ageing/aft089.

34 Mihic S, Harris R. Hypnotics and Sedatives. In: Brunton LL, Chabner BA Knollmann BC, eds. Goodman \& Gilman's The Pharmacological Basis of Therapeutics, 12e. McGraw-Hill, 2011, http://accessmedicine. mhmedical.com.ezp-prod1.hul.harvard.edu/content.aspx?bookid= 374\&Sectionid=41266223, Accessed November 17, 2015.

35 Hammad TA, Laughren T, Racoosin J. Suicidality in pediatric patients treated with antidepressant drugs. Arch Gen Psychiatry 2006;63:332 9. doi:10.1001/archpsyc.63.3.332.

36 Stone M, Laughren T, Jones ML, et al. Risk of suicidality in clinical trials of antidepressants in adults: analysis of proprietary data submitted to US Food and Drug Administration. BMJ 2009;339:b2880. doi:10.1136/bmj.b2880.

37 Romano PS, Roos LL, Jollis JG. Adapting a clinical comorbidity index for use with ICD-9-CM administrative data: differing perspectives. ) Clin Epidemiol 1993;46:1075-9, discussion 1081-90. doi:10.1016/0895-4356(93)90103-8.

38 Rudolph U, Crestani F, Benke D, et al. Benzodiazepine actions mediated by specific gamma-aminobutyric acid(A) receptor subtypes. Nature 1999:401:796-800. doi:10.1038/44579.

39 Vermeeren A. Residual effects of hypnotics: epidemiology and clinical implications. CNS Drugs 2004;18:297-328. doi:10.2165/00023210-200418050-00003.

40 Hansen RN, Boudreau DM, Ebel BE, Grossman DC, Sullivan SD. Sedative Hypnotic Medication Use and the Risk of Motor Vehicle Crash. Am J Public Health 2015;105:e64-9. doi:10.2105/ AlPH.2015.302723. 
41 Wagner AK, Zhang F, Soumerai SB, et al. Benzodiazepine use and hip fractures in the elderly: who is at greatest risk?Arch Intern Med 2004:164:1567-72. doi:10.1001/archinte.164.14.1567.

42 Requena G, Huerta C, Gardarsdottir H, et al. Hip/femur fractures associated with the use of benzodiazepines (anxiolytics, hypnotics and related drugs): a methodological approach to assess consistencies across databases from the PROTECT-EU project.

Pharmacoepidemiol Drug Saf 2016;25:66-78. doi:10.1002/pds.3816.

43 Uhlenhuth EH, Balter MB, Ban TA, Yang K. International study of expert judgment on therapeutic use of benzodiazepines and other psychotherapeutic medications: IV. Therapeutic dose dependence and abuse liability of benzodiazepines in the long-term treatment of anxiety disorders. / Clin Psychopharmacol 1999;19(Suppl 2):23S-9S. doi:10.1097/00004714-199912002-00005.
44 Palmaro A, Dupouy J, Lapeyre-Mestre M. Benzodiazepines and risk of death: Results from two large cohort studies in France and UK. Eur Neuropsychopharmacol 2015;25:1566-77. doi:10.1016/j. euroneuro.2015.07.006

45 Hausken AM, Skurtveit S, Tverdal A. Use of anxiolytic or hypnotic drugs and total mortality in a general middle-aged population. Pharmacoepidemiol Drug Saf 2007;16:913-8. doi:10.1002/pds.1417.

46 Kriegbaum M, Hendriksen C, Vass M, Mortensen EL, Osler M. Hypnotics and mortality--partial confounding by disease, substance abuse and socioeconomic factors?Pharmacoepidemiol Drug Saf 2015;24:779-83. doi:10.1002/pds.3745

47 Neutel Cl, Johansen HL. Association between hypnotics use and increased mortality: causation or confounding?Eur J Clin Pharmacol 2015:71:637-42 doi:10.1007/s00228-015-1841-z.

Supplementary material: eTables 1-3 and eFigure 1 